UDK 343.232:366.542

https://doi.org/10.18485/union_pf_ccr.2021.ch8

\author{
Prof. dr Nataša Mrvić Petrović* \\ Prof. dr Sladana Jovanovići*
}

\title{
PREKRŠAJNOPRAVNA ZAŠTITA POTROŠAČA
}

Apstrakt: Predmet rada je prekršajnopravna zaštita potrošača u srpskom pravu, sagledana u kontekstu aktuelne, segmentirane (i stoga kritikovane) pravne zaštite potrošača. Prekršajnopravna zaštita (uz upravnopravnu, kojoj je takođe poklonjena pažnja) predstavlja supsidijarni mehanizam zaštite, ne tako dobro povezan sa onim primarnim - privatnopravnom zaštitom. Na osnovu analize zakonskih rešenja (vezanih prvenstveno za prekršajnopravnu, ali $i$ upravnopravnu zaštitu potrošača) i primera dobre prakse iz uporednog prava, te rezultata novijih istraživanja, ukazano je na nedostatke postojećeg mehanizma zaštite, te su dati i predlozi za unapređenje zakonodavstva de lege ferenda, kao i za poboljšanje postojeće prakse. Autorke ističu da bi zaštitu prava, interesa i zdravlja potrošača trebalo vezati i za problematiku ostvarivanja ljudskih prava, što podrazumeva uspostavljanje efikasnog sistema upravne i kaznenopravne zaštite, kao i organizacionu usklađenost privatnopravnog i javnopravnog mehanizma zaštite potrošača.

Ključne reči: prava potrošača, inspekcijski nadzor, prekršajnopravna zaštita, Zakon o zaštiti potrošača.

\section{UVOD}

Institucionalni model pravne zaštite potrošača u pravnom poretku Republike Srbije jeste privatnopravni, dok se supsidijarno zaštita postiže merama upravnog nadzora i prekršajnim kažnjavanjem pravnih subjekata koji krše odredbe Zakona o zaštiti potrošača. Kaznenopravna zaštita primenjuje se ultima ratio, kao krajnje sredstvo zaštite potrošača. Funkcija kaznenopravne zaštite u delu koji se odnosi na propisivanje, izricanje i izvršenje prekršajnih sankcija razlikuje se od građanskopravne po tome što treba da obezbedi ostvarivanje javnog interesa u oblasti potrošačkog prava. Poseban značaj prekršajnopravne zaštite potrošača proizilazi iz činjenice da je mehanizam prekršajnog kažnjavanja 2013. godine u fazi pripreme novog zakona o zaštiti potrošača prepoznat kao najefikasniji način koji bi u postojećem pravnom poretku u Republici Srbiji omogućio efikasnu

* Institut za uporedno pravo, Beograd, e-mail n.mrvic@iup.rs

** Pravni fakultet Univerziteta Union u Beogradu, e-mail sladjana.jovanovic@pravnifakultet.rs. Koautorski rad je napisan kao rezultat istraživanja na naučnom projektu Pravnog fakulteta Univerziteta Union u Beogradu - Zaštita kolektivnih interesa potrošača u srpskom i uporednom pravu. 
zaštitu potrošačkog prava u praksi, te je stoga taj model i prihvaćen u zakonu. ${ }^{1}$ Primenu prekršajnih odredaba olakšava činjenica da su prekršaji iz ove oblasti propisani u jednom zakonu - Zakonu o zaštiti potrošača, s tim što će sudija morati u konkretnom slučaju da primenjuje i niz drugih zakona i podzakonskih akata koji regulišu proizvodnju i promet različitih dobara i vršenje usluga.

Obezbeđenje delotvorne sudske zaštite prava potrošača kroz prekršajni postupak utoliko je značajnije za Republiku Srbiju koja se nalazi u postupku pridruživanja Evropskoj uniji, zato što se Direktivom 2011/83/EU Evropskog parlamenta i Saveta o pravima potrošača ${ }^{2}$, najvažnijim aktom kojim se ta oblast celovito reguliše, u uvodnoj odredbi 57. i u poglavlju V (čl. 23. i 24) insistira na tome da države članice EU uvedu i sprovode delotvorne i proporcionalne sankcije, kojima se može postići efekat odvraćanja lica koje krši prava potrošača od takvog postupanja. U tom cilju države članice treba da regulišu pravnu zaštitu potrošača u skladu sa nacionalnim pravom i da omoguće učešće javnih tela i organizacija potrošača koji imaju legitiman interes za zaštitu potrošača u upravnim i sudskim postupcima koji se pokreću tim povodom. U Izveštaju Evropske komisije o praćenju primene Direktive 2011/83/EU³ ukazano je na to da postoje velike razlike $\mathrm{u}$ pogledu regulisanja sankcija $\mathrm{u}$ nacionalnim zakonodavstvima, čime je onemogućena efikasna zaštita potrošača, naročito u prometu roba i usluga na digitalnom tržištu Evropske unije. Stoga je Evropska komisija preporučila kriterijume koji bi trebalo da se primene prilikom propisivanja kazni u nacionalnim zakonodavstvima. ${ }^{4}$

Prema tome, upravni postupak, kao i kažnjavanje u prekršajnom postupku mogu biti adekvatni pravni mehanizmi kojima se uzgredno, uz sudsku zaštitu u

1 European Policy Centre, Policy Brief Towards a European Level of Consumer Protection in Serbia, January 2013, p. 1, (https://cep.org.rs/en/publications/policy-brief-towards-a-european-level-of-consumer-protection-in-serbia/, 14. 7. 2020).

2 Directive 2011/83/EU of the European Parliament and the Council of 25 October 2011 on consumer rights, amending Council Directive 93/13/EEC and Directive 1999/44/EC of the European Parliament and the Council and repealing Council Directive 85/577/EEC and Directive 97/7/EC of the European Parliament and of the Council Text with EEA relevance, OJ L 304, 22. 11. 2011, p. 64-88 (konsolidovana verzija od 1. jula 2018). Konsolidovani tekst Direktive dostupan na: http://data.europa.eu/eli/dir/2011/83/2018-07-01 (25. 8. 2020).

3 Report from the Commission to the European Parliament and the Council on the application of Directive 2011/83/EU of the European Parliament and of the Council of 25 October 2011 on consumer rights, amending Council Directive 93/13/EEC and Directive 1999/44/EC of the European Parliament and of the Council and repealing Council Directive 85/577/EEC and Directive 97/7/EC of the European Parliament and of the Council COM/2017/0259 final, Document 52017DC0259, (https://eur-lex.europa.eu/legal-content/ EN/TXT/?uri=COM\%3A2017\%3A259\%3AFIN, 25. 8. 2020).

4 Prilikom propisivanja vrsti i raspona kazni trebalo bi voditi računa o prirodi, težini, trajanju i trenutnim posledicama kršenja prava potrošača, broju oštećenih potrošača (uključujući i one iz drugih država članica), okolnosti ponuđenog poravnanja ili popravljanja štete, stepenu krivice sa kojim postupa onaj ko krši prava potrošača, finansijskoj dobiti ili gubitku prouzrokovanim takvim kršenjima i drugim okolnostima koje u konkretnom slučaju mogu uticati da kazna bude veća ili manja. Osim novčanih kazni, adekvatno kažnjavanje moglo bi da uključi administrativne zabrane, zaštitne mere i slično. Kako bi se eliminisao tzv. hedonistički proračun kompanije koja na štetu prava potrošača ostvaruje profit, preporučeno je da maksimum novčane kazne najmanje treba da iznosi $4 \%$ od godišnjeg prihoda koji ostvari kompanija u dotičnoj državi članici (Report EU Commission (COM (2017) 259). 
parničnom postupku, obezbeđuje delotvorna zaštita potrošača u praksi. Stoga je cilj rada da se na osnovu analize zakonskih rešenja vezanih za prekršajnopravnu zaštitu potrošača ukaže na moguće nedostatke i predlože rešenja za unapređenje zakonodavstva de lege ferenda, kao i za poboljšanje postojeće prakse. U meri u kojoj je tema rada dopuštala, korišćena su komparativna iskustva kao primeri dobre strane prakse. ${ }^{5} \mathrm{~S}$ obzirom na to da su ovlašćeni organi za podnošenje zahteva za pokretanje prekršajnog postupka pred prekršajnim sudom turistička i tržišna inspekcija, u radu je analiziran i postupak upravnog i inspekcijskog nadzora koji prethodi pokretanju prekršajnog postupka sa ciljem da se ispita povezanost i usklađenost upravne i prekršajnosudske zaštite potrošača.

\section{POVEZANOST UPRAVNOG I PREKRŠAJNOG MEHANIZMA ZAŠTITE POTROŠAČA}

Kažnjavanje subjekta odgovornog za prekršaj iz oblasti zaštite potrošača na osnovu provedenog sudskog postupka predstavlja jednu od mogućih krajnjih posledica prethodno izvršenog upravnog nadzora u kome je nadležni državni organ koji je vršio nadzor ustanovio da se u nezakonitom postupanju nadziranog subjekta stiču obeležja konkretnog prekršaja. Prema članu 154. st. 2. i 3. Zakona o zaštiti potrošača ${ }^{6}$ (dalje: ZZP), upravni nadzor obavljaju organi državne uprave, organi autonomne pokrajine i jedinice lokalne samouprave u okviru delokruga svojih poslova nadležni za sprovođenje propisa o potrošačima i preduzimanje propisanih radnji, dok inspekcijski nadzor, kao deo upravnog nadzora, vrše nadležna ministarstva preko tržišnih inspektora, odnosno preko turističkih inspektora.

Kao i svaki drugi upravni postupak, postupak inspekcijskog nadzora vezano za zaštitu potrošača preduzima se po službenoj dužnosti, a smatra se da započinje preduzimanjem prve radnje inspektora (član 157. stav 1. ZZP). U samom upravnom postupku potrošač čija su prava povređena ili udruženje koje štiti kolektivna prava ne mogu da učestvuju budući da, prema članu 158. stav 2, prijave povrede zakona, odnosno druge informacije, dojave, podnesci i zahtevi podneti radi preduzimanja inspekcijskog nadzora imaju samo dejstvo inicijative za pokretanje postupka, dok podnosioci tih inicijativa nemaju svojstvo stranke u postupku. Takvo rešenje usaglašeno je sa članom 18. stav 3. sistemskog Zakona o inspekcijskom nadzoru ${ }^{7}$ (dalje: ZIN) po kome podnosioci inicijativa za pokre-

Velike razlike u pogledu koncepta prekršaja u anglosaksonskom, kao i unutar kontinentalnog prava (i to između romanske i germanske podvarijante) otežavaju moguća poređenja - vid. Mrvić Petrović, N., Koncepcija prekršaja u uporednom pravu, u: Bobar, K., (ur.), 2002, Zbornik - Prekršajna odgovornost, Beograd, Glosarijum, str. 37-38). Postoji koncepcijska sličnost prava Republike Srbije sa germanskim pravima, ali uz jednu bitnu razliku: u Nemačkoj, Austriji i Švajcarskoj za prekršaje se izriču isključivo novčane kazne te se odlučivanje o prekršajima u prvom stepenu prepušta organima uprave, dok prekršajni sudovi sude u drugom stepenu. U pravnom sistemu Republike Srbije za prekršaje se mogu propisati i izreći i kazne zatvora, što ima za posledicu da su prihvaćena drugačija organizaciona rešenja koja mogu nepovoljno uticati na efikasnost pokretanja i sprovođenja prekršajnog postupka.

6 Sl. glasnik RS, br. 62/14, 6/16 - dr. zakon, 44/18 - dr. zakon.

7 Sl. glasnik RS, br. 36/15, 44/18 - dr. zakon, 95/18. 
tanje postupka inspekcijskog nadzora nemaju svojstvo stranke u postupku koji se pokreće na osnovu te inicijative - aktivnu stranku predstavlja subjekt koji vrši nadzor, dok je u položaju pasivne stranke subjekt koji nadzor trpi. Prema tome, rešenje prihvaćeno u ZZP-u odgovara generalno definisanoj ulozi inspekcije kao državnog organa zaduženog da primenom preventivnih mera obezbedi zakonitost i bezbednost poslovanja i postupanje nadziranih subjekata i da spreči ili otkloni štetne posledice po zakonom i drugim propisom zaštićena dobra, prava i interese, kako je definisano u članu 2. stav 1. ZIN-a. Reč je o tradicionalno prihvaćenom konceptu vršenja upravnih ovlašćenja po službenoj dužnosti i isključivo u javnom interesu, te je otuda subjekt koji prijavljuje kršenje potrošačkih prava sveden na podnosioca predstavke koji i po ZIN-u i po ZZP-u nema čak ni položaj sporednog umešača u upravnom postupku koji je iniciran njegovom predstavkom.

Zakonom o inspekcijskom nadzoru je ipak na poseban način uređen odnos između „informanata“ koji iniciraju pokretanje upravnog postupka i inspekcije koja, bez takvog sudelovanja zainteresovanih lica i oštećenih, teško da bi mogla da sazna za kršenja odgovarajućih propisa i da delotvorno ostvaruje poslove iz svog delokruga. Tako, po članu 18. stav 3. ZIN-a inspektor može pozvati podnosioca predstavke da neurednu predstavku uredi u roku od osam dana (inače će se smatrati da podnosilac odustaje od nje), a takođe je inspektor dužan da podnosiocu pruži određena obaveštenja o sudbini njegove uredne predstavke. Premda se inspekcijski nadzor obavlja ex officio, ipak, po ZIN-u, o celishodnosti pokretanja postupka nadzora inspekcija odlučuje po diskrecionoj oceni, koja se temelji na zakonom prihvaćenom modernom konceptu upravljanja rizikom i procene rizika. ${ }^{8}$ Stoga je u članu 18. stav 5. Zakona o inspekcijskom nadzoru izričito navedeno da inspektor neće pokrenuti postupak po službenoj dužnosti na osnovu predstavke ako je procenjen neznatan rizik ili je posredi zloupotreba prava, te će, prema stavu 6. istog člana ZIN-a, u slučajevima kada utvrdi da ne postoje uslovi za pokretanje postupka po službenoj dužnosti, obavestiti o tome podnosioca predstavke što je pre moguće, a najkasnije u roku od 30 dana od dana prijema predstavke. U slučaju da uvaži predstavku, kako proizilazi iz člana 18. stav 7. ZIN-a, inspektor obaveštava podnosioca predstavke kako je postupio sa predstavkom, i to najkasnije u roku od 15 dana od dana prijema zahteva, a o ishodu pokrenutog postupka vanrednog inspekcijskog nadzora - najkasnije u roku od 15 dana od dana okončanja postupka, s tim što to čini isključivo na (izričit) zahtev podnosioca predstavke, a ne po službenoj dužnosti.

Zakonom o inspekcijskom nadzoru, u članu 157, regulisan je za sve inspekcije jednaki krug ovlašćenja kojima inspektori raspolažu u postupku inspekcijskog nadzora. Odnose se na preduzimanje preventivnih mera, ovlašćenja da se naloži otklanjanje uočenih nepravilnosti u određenom roku i da se nadziranom

8 Zakon o inspekcijskom nadzoru je kao „krovni“ zakon iz te oblasti zamenio brojne zakone i podzakonske propise (smatra se oko 1000). U zakonu je došao do izražaja novi pristup organizovanja i sprovođenja inspekcijskog nadzora, u skladu sa konceptom procene rizika i upravljanja rizikom, a pored toga je ujednačen rad različitih inspekcija (Milić, Lj., Mrvić Petrović, N., 2018, Priručnik za primenu propisa u prekršajnom postupku, Beograd, Institut za uporedno pravo, str. 212-213). 
subjektu zabrani promet robe ili vršenje usluga. $U$ toku inspekcijskog nadzora inspektor može, prema okolnostima slučaja, kombinovano primenjivati preventivna i autoritarna ovlašćenja. Tako inspektor može opomenuti subjekta zbog nezakonitog postupanja i naložiti da se u primerenom roku preduzmu mere za otklanjanje nezakonitosti i štetnih posledica i ispunjavanje zakonskih obaveza (član 27. stav 1. ZIN). Takođe, inspektor može da zabrani obavljanje delatnosti ili vršenje aktivnosti nadziranom subjektu koji ne otkloni nezakonitost u određenom roku ili da zapleni dokumentaciju, robu i druge predmete kojima je subjekt izvršio kršenje propisa ili čiji je nastanak time omogućen (član 28. ZIN). U slučaju da otkrije nezakonitost koja je kažnjiva po zakonu ili drugom propisu, prema članu 42. stav 1. ZIN-a, inspektor je dužan da nadležnom pravosudnom organu podnese krivičnu prijavu, prijavu za privredni prestup ili zahtev za pokretanje prekršajnog postupka, odnosno da izda prekršajni nalog, a pored toga, prema stavu 2. istog člana, dužan je i da preduzme druge radnje i mere na koje je zakonom ili drugim propisom ovlašćen (npr. iniciranje privremenog ili trajnog oduzimanja dozvole).

Zakonodavac nije iskoristio mogućnost da Zakonom o zaštiti potrošača propiše specijalna ovlašćenja inspektora kada vrše inspekcijski nadzor u toj oblasti. Član 156. ZZP-a u kome su navedena ovlašćenja inspektora je nomo-tehnički tako koncipiran da je u prvom stavu navedeno generalno da inspektor ima ovlašćenja iz ovog i drugih zakona, dok su u stavovima 2. i 3. enumeracijom navedene sve situacije u kojima se preduzima inspekcijski nadzor (isto rešenje bilo je prihvaćeno i u ranijem istoimenom zakonu iz 2010. godine). Inspektor je ovlašćen da naloži nadziranom subjektu da u određenom roku, ne kraćem od 24 sata, a ne dužem od dva meseca, otkloni uočene nepravilnosti i da, subjektu koji nije postupio po nalogu za otklanjanje nepravilnosti, rešenjem privremeno zabrani promet robe, odnosno vršenje usluga (član 157). Smatramo da nomotehnički način na koji su propisana ovlašćenja nadležnih inspekcija, koji nameće obavezu inspektoru da u svakom konkretnom slučaju ceni kada će koje ovlašćenje primeniti, otvara put neujednačenoj praksi, a relativno mala ovlašćenja inspektora ograničavaju mogućnosti njegovog efikasnog delovanja. Kao primer boljeg nomotehničkog pristupa može poslužiti glava IX (čl. 70. do 73) slovenačkog Zakona o zaštiti potrošača ${ }^{9}$ od 26. 2. 1998. godine, sa kasnijim izmenama: za svaku situaciju u kojoj se vrši inspekcijski nadzor jasno je naznačeno koje će posebno ovlašćenje inspektor iskoristiti. Pri tome, inspektor ima sledeća posebna ovlašćenja: 1) da naredi da nadzirani subjekt izvrši osnovani zahtev potrošača; 2) da donese odluku kojom zabranjuje prodaju robe do otklanjanja nepravilnosti; 3) da donese odluku kojom obavezuje nadziranog subjekta da ispuni zakonsku obavezu; 4) da donese odluku o zabrani oglašavanja ili reklamiranja ili da zabrani objavljivanje oglasa pripremljenog za objavljivanje. Tako, po članu 71. slovenačkog Zakona o zaštiti potrošača, slovenačka tržišna inspekcija ima pravo da naloži nadziranom subjektu da odobri zahtev potrošača ili vrati iznos plaćen za robu ako subjekt odbije ne-

9 Zakon o varstvu potrošnikov (ZVPot), Uradni list RS, br. 98/04 sa izmenama, poslednjim u br. 31/18 od 4. 5. 2018. Prečišćeni tekst dostupan na: http://www.pisrs.si/Pis.web/pregledPredpisa?id=ZAKO513 (10. 7. 2020). 
opravdano na zahtev potrošača da otkloni kvar na robi, zameni neispravnu robu ili vrati deo plaćene cene srazmerno oštećenju kupljene stvari.

Čini se da je slovenački zakonodavac vodio računa da olakša postizanje svrhe inspekcijskog nadzora i obezbedi njegovu delotvornost koja nije samo u javnom interesu da se uspostavi red na tržištu, nego i u interesu rešavanja konkretnog „potrošačkog problema“, dok je rešenjem u ZZP-u Republike Srbije samo zadovoljena obaveza propisivanja formalnih pretpostavki inspekcijskog nadzora. Tako inspekcijski nadzor rezultira merama koje nužno ne moraju da doprinesu rešenju „potrošačkog problema“ povodom koga se nadzor vrši, a potrošač se „šeta“ u trouglu tržišne inspekcije, udruženja za zaštitu potrošača i suda, primoran da se dobro obavesti za koje je radnje i postupke koji organ ili telo zaduženo (sa neizvesnim izgledima da svoj „problem“ efikasno reši). Zbog čega inspektor koji je u postupku inspekcijskog nadzora konstatovao da je potrošač u pravu kada je podneo reklamaciju ne bi mogao da izda nalog nadziranom subjektu da se postupi po opravdanom zahtevu potrošača, na primer, osim što će samo naložiti da se potrošaču odgovori na reklamaciju? Prema našem ZZP-u inspektor nema takva ovlašćenja: on može naložiti trgovcu da odgovori na reklamaciju, ali mu ne može naložiti da je uvaži, jer će se osnovanost zahteva potrošača procenjivati u postupku posredovanja sa potrošačem ili udruženjem koje štiti kolektivna prava potrošača ili u okviru sudskog postupka. Slovenački primer je drugačiji. Štaviše, pokazuje se da se u Sloveniji potrošači od nepoštene poslovne prakse štite pojačano primenom širih ovlašćenja koje ima organ koji vrši upravni nadzor. Za razliku od našeg zakona, u kome se u članu 153. upućuje oštećeni da u postupku pred sudom ostvaruje zahtev za naknadu štete, za poništaj ili utvrđivanje ništavosti ugovora ili na drugi postupak za ostvarivanje prava, u članu 12. stav 2. slovenačkog Zakona o zaštiti potrošača od nepoštene poslovne prakse $\mathrm{e}^{10}$ od 31. 5. 2007. godine predviđeno je da organ koji vrši upravni nadzor može da odluči o naknadi štete oštećenom potrošaču (član 12. stav 2). Nadležni organ je dužan i da preduzme mere za zaštitu prava trećih lica, povređena postupcima nadziranog subjekta koji je kršio zakon ili drugi propis (član 29. Zakona o zaštiti potrošača od nepoštene poslovne prakse). Takođe, umesto „nemušte“ odredbe iz našeg ZZP-a kojom se teret dokazivanja prebacuje sa potrošača na subjekta koji krši njegova prava, u članu 14. slovenačkog Zakona o zaštiti potrošača od nepoštene poslovne prakse izričito je predviđeno da se i u upravnom i u sudskom postupku teret dokazivanja uređuje tako da se suprotnoj strani ostavlja rok od osam dana da iznese istinite navode o spornoj praksi, a ako taj rok propusti, ili ako izneti navodi nisu dovoljni, smatraće se neistinitim, čime je jasno precizirano na koji će se način zakonska prezumpcija primenjivati u praksi.

Sve navedeno pokazuje da je slovenački zakonodavac svestan da „potrošački problem“ treba rešiti što pre, na ujednačen način i odjednom. Za razliku od tog pristupa, inspekcijski nadzor u Srbiji koji u oblasti prava potrošača vrše tržišna i turistička inspekcija, zbog načina kako je regulisan ZZP, neće moći da bude efikasan. Treba napomenuti da je u jednoj studiji iz 2013. godine ukazano na to da se tržišna inspekcija nedovoljno angažuje na poslovima iz ove oblasti, navodno 
„zbog nepostojanja zakonskih mogućnosti za delovanje“. ${ }^{11}$ Budući da ovlašćenja tržišnih inspektora, u odnosu na raniji Zakon o zaštiti potrošača iz 2010. godine, nisu povećana (povećan je obim njihovih zadataka kroz veći broj slučajeva u kojima vrše nadzor), moglo bi se konstatovati da se situacija nije bitnije izmenila, te će i dalje potrošač morati da se raspituje i gubi vreme oko toga da li treba da se obrati tržišnoj inspekciji ili udruženju potrošača i procenjujući da li bi bilo celishodno da pokrene sudski postupak ili ne.

\section{PODNOŠENJE ZAHTEVA ZA POKRETANJE PREKRŠAJNOG POSTUPKA}

Tržišna i turistička inspekcija ili drugi organ zadužen za vršenje upravnog nadzora dužni su da podnose zahtev za pokretanje prekršajnog postupka ili da izdaju prekršajni nalog ako otkriju nezakonitost koja je propisana kao prekršaj. $\mathrm{Na}$ taj način formulisano je načelo legaliteta pri gonjenju za prekršaje u članu 42. stav 1. ZIN-a, ali je istim zakonom u stavu 3. predviđen i izuzetak od tog načela. Ratio legis tog izuzetka jeste necelishodnost primene represivnih ovlašćenja i pokretanja kaznenih sudskih postupaka prema nadziranim subjektima koji su naknadno otklonili protivpravno stanje i nadoknadili pričinjenu štetu. ${ }^{12}$ Diskrecionu ocenu o (ne)celishodnosti pokretanja prekršajnog postupka ili izdavanja prekršajnog naloga inspektor može doneti u dva slučaja: 1) ako se radi o lakšem prekršaju (za koji propisani posebni maksimum novčane kazne ne prelazi 200.000 dinara i nije predviđena zaštitna mera) pod dopunskim kumulativno propisanim uslovom da je nadzirani subjekt pre ili tokom upravnog nadzora, pre izricanja mera u zapisnik ili u naknadno ostavljenom roku izvršio naloge ili predloge inspekcije, otklonio nezakonitost i štetne posledice radnje prekršaja, ako ih je bilo i 2) ako je nadzirani subjekt, pre pokretanja postupka inspekcijskog nadzora ili pre nego što je obavešten o predstojećem inspekcijskom nadzoru, samoinicijativno prijavio nezakonitost $\mathrm{i}$, ako ih je bilo, otklonio posledice povrede propisa, odnosno upotrebio sva sredstva koja su mu na raspolaganju da se te posledice otklone. Tako je, iz pragmatičnih razloga, u ZIN uvedeno načelo oportuniteta u gonjenju za prekršaje i izdavanje prekršajnih naloga iz delokruga različitih inspekcija, jedinih ovlašćenih državnih organa da neposredno nadziru primenu zakona iz odgovarajućih oblasti. „Ustupak“ formalnom proklamovanom načelu legaliteta u članu 42. stav 1 . ZIN-a jeste to što je inspektor obavezan

11 Lazarević, N. et al., 2013, Studija potrošačke politike u Srbiji: ka evropskom nivou zaštite potrošača u Srbiji, Beograd, Centar za evropske politike, str. 37.

12 To nije stvarno kajanje, budući da je učinilac već dovršio formalni delikt - prekršaj. Reč je o svojevrsnoj „amnestiji“ za one koji se samooptuže i/ili naknadno otklone protivpravno stanje kojom se rasterećuje upravni i sudski sistem od bagatelnih slučajeva, a ta opcija je mnogo povoljnija za učinioca koji na taj način izbegava troškove prekršajnog postupka i osudu (pa makar i sa izgledom da bude oslobođen od kazne). Isti institut se primenjuje kod poreskih prekršaja i kod nas i u inostranstvu. O tome vid. Mrvić Petrović, N., Značaj naknadnog izvršenja poreske obaveze na kažnjavanje za poreske delikte, u: Kostić, J., Stevanović, A. (ur.), 2018, Finansijski kriminalitet, Beograd, Institut za uporedno pravo i Institut za kriminološka i sociološka istraživanja, str. 120-122. 
da konstatuje u zapisniku o inspekcijskom nadzoru da nije podneo zahtev za pokretanje prekršajnog postupka, odnosno da nije izdao prekršajni nalog i da navede odgovarajuće obrazloženje (član 42. stav 9. ZIN-a), a takođe ima obavezu da pojačano prati nastavak poslovanja i postupanja nadziranog subjekta koga nije gonio za prekršaj (član 42. stav 5. ZIN). Inspektor, međutim, uvek mora podneti zahtev za pokretanje prekršajnog postupka prema nadziranom subjektu koji ponavlja prekršaj, i to bez obzira da li je prvi put protiv njega bio podnet zahtev za pokretanje prekršajnog postupka ili je bio izdat prekršajni nalog, kao i u slučaju kada prekršaj učini neregistrovani subjekt (član 42. stav 4. ZIN).

Primena načela oportuniteta iz člana 42. stav 3. ZIN-a može se u ograničenoj meri koristiti za prekršaje propisane ZZP-om. Diskreciono odlučivanje inspektora o izdavanju prekršajnog naloga isključeno je samim tim što ZZP takvu mogućnost ne predviđa. Prema tome, primena člana 42. stav 3. ZIN-a moguća je samo u pogledu procene potrebe podnošenja prekršajne prijave za prekršaje iz člana 160. stav 1. u vezi sa stavom 2. ZZP-a koje učini fizičko lice ili odgovorno lice u pravnom licu, budući da je za te prekršaje predviđena kazna čiji je posebni maksimum 150.000 dinara (ne dostiže 200.000 dinara). Načelo oportuniteta može se primeniti u svakom slučaju u odnosu na prekršaje za koje odgovara fizičko lice. Kako je, međutim, za pojedine prekršaje odgovornog lica u pravnom licu predviđena mogućnost izricanja zaštitne mere zabrane vršenja određenih poslova u trajanju od tri meseca do jedne godine, a to su, prema članu 161. stav 2 , radnje prekršaja iz člana 160 . stav 1 . tač. 9), 10), 11), 12) i 54) ${ }^{13}$ (među kojima su i slučajevi nepoštene, obmanjujuće i nasrtljive prakse), inspektor bi morao po službenoj dužnosti da podnese prekršajnu prijavu protiv odgovornog lica za navedene prekršaje, dok bi u odnosu na sve ostale prekršaje propisane u članu 160, ako ih izvrši to lice, inspektor mogao da postupi po načelu oportuniteta. Drugi subjekti odgovorni za prekršaj (preduzetnik ili pravno lice) podležu uvek prekršajnom gonjenju za učinjene prekršaje iz ZZP-a, s tim što bi postupci kojima naknadno otklanjaju protivpravno stanje ili štetne posledice svojih radnji mogli da utiču da ih sud oslobodi kazne po članu 44. stav 2. Zakona o prekršajima ${ }^{14}$ (dalje: ZP) ili bi te okolnosti sud mogao da uvaži kao olakšavajuće okolnosti prilikom odmeravanja kazne, shodno članu 42. ZP-a.

Tržišna, turistička inspekcija ili drugi nadležan organ uprave ili lokalne samouprave koji sprovodi upravni nadzor nad primenom Zakona o zaštiti potrošača učestvuje u pokrenutom prekršajnom postupku u svojstvu ovlašćenog podnosioca zahteva za pokretanje prekršajnog postupka. U slučaju da ovlašćeni organ ne podnese zahtev, moguće je da se u ulozi podnosioca zahteva za pokretanje prekršajnog postupka javi potrošač, kao oštećeni (član 126. ZP). Bez obzira na to što je tada njegov procesni položaj izjednačen sa položajem ovlašćenog organa, potrošač teško može sam pribaviti dokaze kojima će potkrepiti svoj zahtev, posebno ako je pojedinačni sudski slučaj izolovani primer sistematski preduzimane nepoštene poslovne prakse, ako se sudski postupak vodi protiv inostranog

13 Za iste prekršaje mogu se odrediti odgovarajuće zaštitne mere i drugim subjektima odgovornim za prekršaj: pravnom licu i preduzetniku (član 161. ZZP).

14 Sl. glasnik RS, br. 65/13, 13/16, 98/2016 - odluka US, 91/2019 - dr. zakon. 
pravnog lica i slično. Oštećeni ima pravo da u prekršajnom postupku ostvaruje imovinskopravni zahtev, ali je ta mogućnost više teorijska nego što se koristi u praksi. Prema tome, učešće nadležnih državnih organa u ulozi podnosioca zahteva za pokretanje prekršajnog postupka omogućava delotvornije isleđivanje okolnosti pod kojima je došlo do kršenja potrošačkih prava. Praksa izbegavanja javnog tužioca da ostvaruje zakonska ovlašćenja stranke u prekršajnom postup$\mathrm{ku}$ (član 127. ZP) rezultira time da se ne prepoznaje moguća povezanost prakse kršenja potrošačkih prava, čak ni kada dovodi do učestalog kažnjavanja istog pravnog lica za prekršaje, sa privrednim kriminalitetom i prevarama na štetu potrošača. ${ }^{15}$

\section{BITNA OBELEŽJA PREKRŠAJA IZ ZAKONA O ZAŠTITI POTROŠAČA}

U Zakonu o zaštiti potrošača, u glavi XVI, propisane su kaznene odredbe na osnovu kojih se kažnjavaju za prekršaje pravno lice, preduzetnik, fizičko lice i odgovorno lice u pravnom licu za nepoštovanje određenih obaveza ili kršenje zabrana koje su predviđene ovim zakonom. Postupanja različitih kategorija odgovornih subjekata definisana su na jednaki način - jedina razlika je u rasponima propisanih novčanih kazni koje se mogu izreći za prekršaje pojedinim od navedenih subjekata. Način na koji su propisane novčane kazne onemogućava izdavanje prekršajnog naloga. Time je dodatno ugroženo efikasno delovanje nadležnih inspekcija na sprečavanju prekršaja iz oblasti zaštite potrošača, budući da bi, u suprotnom, na osnovu člana 169. ZP-a bili u mogućnosti da izdaju prekršajni nalog čim ustanove izvršenje prekršaja na osnovu izvršenog inspekcijskog nadzora. U nedostatku te mogućnosti, nadležne inspekcije podnose zahteve za pokretanje prekršajnog postupka, koji često zastarevaju zbog kratkih rokova zastarevanja propisanih u ZP-u i preopterećenosti prekršajnih sudova.

Radnje prekršaja iz člana 160. ZZP-a propisane su većinom kao nečinjenja, što je i inače svojstveno prekršajima, naročito u oblasti privrednog poslovanja. ${ }^{16}$ Od 54 propisana prekršaja, $64 \%$ ima definisane radnje izvršenja kao prava nečinjenja. Za postojanje tih prekršaja dovoljno je dokazati da je učinilac bio dužan da nešto učini prema odgovarajućoj odredbi ZZP-a i da to nije učinio ili da to nije učinio $u$ određenom roku, a mogao je u datoj situaciji. Upravo za većinu opisanih prekršaja koji su očigledni (npr. neisticanje cene, nepoštovanje roka za odgovor na reklamaciju, neisporuka robe potrošaču u propisanom zakonskom roku i sl.) bilo bi celishodno uvesti prekršajni nalog.

Prekršaji koji se čine aktivnim delovanjem, kao i oni čije su radnje izvršenja definisane kao činjenja, a mogu se izvršiti i propuštanjem (tzv. neprava

15 Za razliku od toga, u inostranstvu je davno prepoznata ta povezanost, kako pokazuje izveštaj Federalnog tužilaštva u Sjedinjenim Američkim Državama (Attorney General's First Annual Report, Federal Law Enforcement and Criminal Justice Assistence Activities, 1972, US. Department of Justice, Washington, D.C., p. 503), https://babel.hathitrust.org/cgi/pt?id=mdp.39 015028782459\&view=1up\&seq=20 (20. 7. 2020).

16 Mrvić Petrović, N., 2014, Komentar novog Zakona o prekršajima, Beograd, Paragraf Lex, str. 20. 
nečinjenja) nešto se teže dokazuju, naročito ako je kao bitno obeležje prekršaja predviđeno da takvom radnjom treba da je ostvarena posledica (u vidu povrede ili konkretnog ugrožavanja). Među takvim prekršajima posebno se ističu radnje prekršaja obavljanja nepoštene poslovne prakse i drugih njenih pojavnih oblika: obmanjujuće i nasrtljive poslovne prakse (definisani u čl. 160. stav 1. u tač. 8-10). Prema članu 18. stav 6. ZZP-a nepoštenom se naročito smatra obmanjujuća poslovna praksa i nasrtljiva poslovna praksa, te prekršaji kojima se sankcionišu takve prakse (definisani u članu 160. stav 1. u tač. 9. i 10) predstavljaju specijalne oblike prekršaja obavljanja nepoštene prakse iz člana 160. stav 1. tačka 8 . Između navedenih prekršaja postoji odnos prividnog idealnog sticaja, što može biti komplikacija prilikom primene norme, budući da podnosilac zahteva treba da pravilno sumpsumira činjenično stanje pod pravnu normu i da proceni da li se radi o „običnoj“ nepoštenoj praksi ili o njenim specijalnim vidovima kakve predstavljaju obmanjujuća i nasrtljiva poslovna praksa. Primena ovih odredaba zahteva da se tumači kada se u postupcima okrivljenog za prekršaj stiču obeležja kog prekršaja, što može biti skopčano sa teškoćama uprkos tome što je u ZZP-u, u glavi III, definisano kakvo se postupanje smatra nepoštenom poslovnom praksom. Tako se pod nepoštenu praksu podvodi: povezanost usluga iznajmljivanja grobnog mesta i prodaje pogrebne opreme koju vrši pogrebno društvo, pogrešna ili netačna najava sniženja robe u prodaji, navođenje klijenta da poveruje da davalac pruža medicinske usluge aparatom koji se nudi na prodaju, naplata troškova upravljanja dospelim bankarskim kreditom čiji je iznos veći od zatezne kamate i troškova naknade prema odgovarajućoj poslovnoj praksi, lažne „besplatne“ ponude i „posebne“ pogodnosti, manipulacije decom ili iskorišćavanje činjenice da su potrošači koji spadaju u „ranjive“ kategorije (deca, stariji, bolesni i sl.) zbog nedostatka iskustva, znanja ili zbog posebnih potreba prijemčivi za kupovinu određenih roba ili korišćenje usluga, prikriveno oglašavanje u medijima (kada kompanija finansira objavljivanje članka, što nije izričito navedeno, u kome se preporučuju njeni proizvodi), piramidalni sistemi itd.

Posebno se kod prekršaja učinjenih kršenjem potrošačkih prava može postaviti pitanje u kom vremenu je bio izvršen prekršaj i na kom mestu, što su elementi neophodni za činjeničnu identifikaciju prekršaja, a sa kojima u vezi postoje i problemi u praksi. ${ }^{17}$

Vreme izvršenja prekršaja (tempus commissi delicti) procenjuje se, kao i u krivičnom pravu, prema teoriji delatnosti. To je ono vreme kada je radnja preduzeta ili kada je učinilac propustio radnju koju je bio dužan da preduzme. Kod prekršaja čija je radnja određena kao činjenje, a to će biti prekršaji obavljanja nepoštene, obmanjujuće i nasrtljive poslovne prakse, vreme izvršenja poklapa se sa datumom kada je prekršaj otkrilo službeno lice koje vrši upravni ili inspekcijski nadzor, preduzimajući radnje na koje je ovlašćeno. To može biti trenutak kada je učinilac zatečen in flagranti (npr. kada se na osnovu člana 21a ZIN-a koristi institut prikrivene kupovine, kako bi se obezbedili dokazi o poslovanju neregistrovanog subjekta ili o neizdavanju računa). Češće se dešava da se vreme prekršaja i

17 Jeličić, N., 2019, Činjenična identifikacija prekršaja, NBP: Žurnal za kriminalistiku i pravo, 2, str. 146. 
datum vršenja inspekcijskog nadzora ne poklapaju, budući da je do nadzora došlo kasnije (u tom slučaju merodavno je vreme izvršenja nadzora). Kada je organ uprave prilikom upravnog nadzora rešenjem odredio rok nadziranom subjektu da nešto otkloni ili izvrši, okrivljeni koji nije postupio po tom nalogu nalazi se u prekršaju od prvog narednog dana posle proteka roka. Ponekad čak nije moguće tačno utvrditi vreme izvršenja prekršaja, kada se obično u prijavi navodi najbliže okvirno vreme preduzete radnje ili se opredeljuje početak i završetak perioda u kome je radnja preduzeta, ili se čak može navesti da je radnja preduzeta „,neutvrđenog dana" u određenom periodu, pod uslovom da taj period nije sporan, kao ni radnja. ${ }^{18}$ Potrebno je odrediti početak i završetak perioda - „neutvrđenog dana od ... do", a od početka označenog perioda teče rok zastarelosti. ${ }^{19}$

Vreme izvršenja prekršaja propuštanja utvrđuje se prema danu kada je subjekt bio dužan da postupi po pravnoj normi (pravo nečinjenje) ili, kod nepravih nečinjenja, kada je bio dužan da spreči nastanak zabranjene posledice, pod uslovom da je to bio dužan i mogao da učini. Kod onih prekršaja koji se čine propuštanjem da se nešto učini u zakonskom roku (kao, na primer, kod prekršaja iz člana 160. stav 1. tačka 33) ZZP-a, kada prodavac ne odgovori potrošaču na izjavljenu reklamaciju na način i u roku predviđenom članom 56. stav 7, odnosno članom 81. stav 3 ), kao vreme prekršaja računa se prvi naredni dan nakon isteka zakonskog roka, bez obzira na to kada je učinilac otkriven u prekršaju. ${ }^{20}$ Takođe i rokovi zastarelosti počinju da teku prvog narednog dana po isteku roka za ispunjenje obaveze. Međutim, kada nečinjenje nije vezano za propisani rok, nego postoji stalna obaveza na činjenje, kao u slučaju kada prodavac ne izda potrošaču garantni list (prekršaj iz člana 160. stav 1. tačka 28), vreme izvršenja prekršaja vezuje se za dan otkrivanja prekršaja, a od tog dana teče i rok zastarelosti pokretanja prekršajnog postupka. ${ }^{21}$

Kod produženog prekršaja učinjenog činjenjem, vreme izvršenja procenjuje se prema momentu preduzimanja poslednje radnje koja ulazi u sastav produženog dela, a kod trajnog prekršaja bilo bi merodavno vreme kada je dovršena radnja izvršenja. Kod produženog ili trajnog prekršaja učinjenog nečinjenjem, vremenom izvršenja prekršaja smatra se ono kada radnja više uopšte ne bi mogla da se preduzme ili kada njeno naknadno preduzimanje ne bi sprečilo nastanak posledice. $^{22}$

Ponekad kod prekršaja iz oblasti zaštite potrošača može biti problem da se ustanovi tačno mesto izvršenja prekršaja, naročito kod tzv. distancionih delikata,

18 Mrvić Petrović, N., 2014, str. 21-22.

19 Delibašić, T., Analiza spornih pitanja prakse carinskih prekršaja kroz izvode presuda, u: Spahić, S. et al. (ur.), 2013, Zbornik sudske prakse, Beograd, Udruženje sudija prekršajnih sudova Republike Srbije, str. 146.

20 Veće za prekršaje u Beogradu, Up. $3463 / 95$ od 29. 12. 1995. (nav. prema: Mrvić Petrović, N., 2014, str. 21).

21 Pravni stav broj 3 Višeg prekršajnog suda od 22. 3. 2010. godine (Delibašić T., 2012, Praktična primena Zakona o prekršajima, Beograd, Službeni glasnik, str. 42). Ovakav stav u slučajevima postojanja stalne obaveze na činjenje potvrdio je i Vrhovni kasacioni sud: Przz. 32/11 od 30. 3. 2012.

22 Mrvić Petrović, N., 2014, str. 21. 
kod kojih je radnja izvršenja preduzeta na jednom mestu, a posledica nastaje na drugom mestu (na primer kod on-line kupovine koja je, zbog svojih osobenosti i značaja, posebno regulisana u ZZP-u). Prema članu 12. ZP-a, kojim je prihvaćena teorija ubikviteta, prekršaj se smatra izvršenim kako u mestu gde je učinilac radio ili bio dužan da radi, tako i u mestu gde je posledica nastupila. Kod nečinjenja bi to svakako bilo ono mesto gde je učinilac bio dužan aktivno da deluje, a ako nije moguće tačno utvrditi to mesto, onda bi se moglo smatrati mestom izvršenja ono u kome je trebalo da preduzme određene radnje, što se često poklapa sa mestom u kome se nalazi organ koji je subjektu naložio izvršenje određene obaveze. ${ }^{23}$

\section{ZAKLJUČAK}

Upravni, odnosno inspekcijski nadzor u okviru upravnog nadzora i prekršajno kažnjavanje su u zakonodavstvu Republike Srbije uzgredni (supsidijarni) načini zaštite potrošačkih prava - redovan put kojim potrošači ostvaruju svoja prava jeste parnica. Prema tome, u postupku upravnog ili inspekcijskog nadzora koji se vodi povodom kršenja prava potrošača nije moguće ostvarivanje interesa pojedinog oštećenog potrošača in concreto, nego se kroz generalna ovlašćenja (po sistemskom zakonu o inspekciji) i posebna ovlašćenja (po ZZP-u) prilikom vršenja inspekcijskog nadzora ostvaruje zaštita prava potrošača kao „difuzne“ grupe neidentifikovanih oštećenih lica, i to isključivo u „višem“, tj. javnom interesu da se poboljšanjem zaštite potrošača obezbedi slobodna tržišna utakmica.

Striktno razdvajanje procesnih puteva: onih kojima se realizuje javni interes (upravni i prekršajni postupak) od drugih u okviru kojih se ostvaruje primarno privatni interes potrošača (parnica, vansudsko poravnanje) jeste, prema tome, koncept na kome se temelji zaštita potrošačkog prava u našem pravnom sistemu, koji odgovara institucionalnom modelu privatnopravne zaštite potrošača. Isti model prihvaćen je u nemačkom pravnom sistemu i ispoljava niz prednosti, ali i nedostataka. Prema rezultatima istraživanja izvršenog u Nemačkoj 2018. godine (Podszun i dr., 2018), navedeni koncept ima prednosti kada se reaguje privremenim sudskim zabranama u parničnom postupku, na osnovu zakona koji regulišu zabranu nelojalne konkurencije (Gesetz gegen den unlauteren Vettbeverb, UVG) i podnošenje tužbi zbog propuštanja (Unterlassungsklagengesetz, UKlaG). Primeri sudskih odluka, međutim, ostaju nepoznati javnosti. Privatnopravni model nije dovoljno efikasan u slučajevima kada nije moguće, ili bi to bilo skopčano sa nesrazmernim naporom i troškovima, da sam potrošač razjasni okolnosti slučaja u kome, na primer, učestvuju inostrane kompanije ili je slučaj povezan sa finansijskim malverzacijama, netransparentnim poslovanjem kompanije i slično.

Takođe, privatnopravni model ne omogućava naknadu šteta koje su pričinjene neidentifikovanom broju lica, a potrošač, iz racionalnih razloga, iz- 
begava da pokrene parnicu kada je pretrpeo manju štetu. Stoga model ne omogućava efikasno obeštećenje potrošača, a, takođe, ostaju nerešeni i javnosti nepoznati slučajevi učestalih sitnih prestupa privrednih subjekata koji posluju uz kršenje prava potrošača. Uočeni nedostaci, kako predlažu istraživači, mogu se prevazići bolje koordinisanom saradnjom privatnog i javnog sektora zaštite potrošača. Najveća prednost javnopravne zaštite jeste delotvorna istraga slučaja kršenja prava potrošača, koja je posebno značajna kada je potrebno obezbediti zaštitu prava potrošača u digitalnom okruženju, budući da kršenje tih prava redovno šteti velikom broju potrošača. Istraživači su konstatovali i da sistem prioritetne primene privatne zaštite potrošača u Nemačkoj sprečava da se u potpunosti iskoriste mere i nadležnosti koje pruža Evropska mreža za zaštitu potrošača. ${ }^{24}$

Kako pokazuje nemački primer, a rezultati navedenog istraživanja mutatis mutandis bi mogli da se odnose i na Srbiju, dosledna primena koncepta razdvojenosti privatnopravnog i javnopravnog mehanizma zaštite potrošača onemogućava da se iskoriste sve prednosti brzih postupaka (upravnog i prekršajnosudskog postupka) u cilju postizanja efikasne zaštite interesa pojedinog potrošača. Potrošač koji ima „potrošački problem“, kako se to kaže, upućen je da meritornu odluku suda obezbedi pokretanjem parničnog postupka, pri čemu je izložen troškovima, rizicima relativno dugog trajanja postupka i neizvesnog ishoda. Zaštita potrošačkih prava se supsidijarno postiže kroz mehanizam upravnog i prekršajnog postupka, i to u onoj meri u kojoj se način ostvarivanja javnog interesa poklapa sa individualnim interesom potrošača „koji ima potrošački problem“. $\mathrm{Ne}$ može se očekivati da će se potrošač odlučiti na pokretanje sudskog spora zbog male vrednosti robe prilikom čije je kupovine obmanut, te bi zato trebalo pronaći načine da se de lege ferenda kroz upravni postupak i prekršajni postupak unapredi zaštita potrošača. U tom pogledu čini se da bi bilo korisno proširiti ovlašćenja inspektora, naročito u vezi sa otkrivanjem nepoštene poslovne prakse, kao što je učinjeno u slovenačkom zakonodavstvu (a odgovara rešenjima koja su, vezano za inspekcijski nadzor, bila prihvaćena u pravu nekadašnje SFRJ). Pored toga, u sadašnjoj situaciji „razdrobljenosti“" načina zaštite prava potrošača, neophodno je obezbediti izuzetno dobru koordinaciju, kako bi potrošač odmah bio upućen na koji način da ostvari svoja prava.

Pravo zaštite potrošača predstavlja segment pravnog sistema u kome se najviše teži stvaranju takvih uslova na tržištu koji bi omogućili nesmetano kretanje roba i ljudi, u skladu sa osnovnim postulatima prava Evropske unije. Zbog toga, uporedo sa težnjom da se zaštita potrošača izmenama zakona u svemu uskladi sa pravom Evropske unije (pa i uvođenjem visokih novčanih kazni kompanijama koje krše pravila EU u toj oblasti) trebalo bi obezbediti još bolje organizaciono

24 Podszun, R., Busch, C., Henning-Bodewig, F., 2018, Behördliche Durchsetzung des Verbraucherrechts? Darstellung und Systematisierung von Möglichkeiten und Defiziten der privaten Durchsetzung des Verbraucherschutzes sowie Einbeziehung der Kartellbehörden zu dessen Durchsetzung, Studie im Auftrag des Bundesministeriums für Wirtschaft und Energie, Februar 2018, str. 297-298, (https://www.bmwi.de/Redaktion/DE/Publikationen/Studien/behoerdlichedurchsetzung-des-verbraucherrechts.pdf?__blob=publicationFile\&v=10, 20. 7. 2020). 
usklađivanje upravne i sudske zaštite potrošača, pri čemu, naročito u prekršajnom postupku, treba dopustiti mogućnost da zahtev za pokretanje prekršajnog postupka podnose i zastupaju organizacije zadužene za ostvarivanje kolektivnih prava potrošača. Prvi razlog za to je što se zaštitom potrošača ostvaruje važan zadatak sprečavanja poslovnih malverzacija i privrednog kriminaliteta. Međutim, osim zaštite ekonomskih interesa potrošača i slobodne konkurencije na (digitalnom) tržištu, trebalo bi da je još jasnije prepoznato da se zaštita prava, interesa i zdravlja potrošača vezuje i za ostvarivanje ljudskih prava, što pretpostavlja uspostavljanje efikasnog sistema upravne i kaznenopravne zaštite potrošača.

\section{LITERATURA}

1. Attorney General's First Annual Report, Federal Law Enforcement and Criminal Justice Assistance Activities, 1972, US, Department of Justice, Washington, D.C., p. 503, (https://babel.hathitrust.org/cgi/pt?id=mdp.39015028782459\&view=1up\&s eq=20, 20. 7. 2020).

2. Delibašić, T., 2012, Praktična primena Zakona o prekršajima, Beograd, Službeni glasnik.

3. Delibašić, T., Analiza spornih pitanja prakse carinskih prekršaja kroz izvode presuda, u: Spahić, S. et al. (ur.), 2013, Zbornik sudske prakse, Beograd, Udruženje sudija prekršajnih sudova Republike Srbije.

4. European Policy Centre, Policy Brief Towards a European Level of Consumer Protection in Serbia, January 2013, (https://cep.org.rs/en/publications/policy-brieftowards-a-european-level-of-consumer-protection-in-serbia/, 14. 7. 2020).

5. Jeličić, M., 2019, Činjenična identifikacija prekršaja, NBP: Žurnal za kriminalistiku $i$ pravo, 2.

6. Lazarević, N., Đurović, M., Lazarević, M., Đinđić, M., 2013, Studija potrošačke politike u Srbiji: ka evropskom nivou zaštite potrošača u Srbiji, Beograd, Centar za evropske politike.

7. Milić, Lj., Mrvić Petrović, N., 2018, Priručnik za primenu propisa u prekršajnom postupku, Beograd, Institut za uporedno pravo.

8. Mrvić Petrović, N., 2014, Komentar novog Zakona o prekršajima, Beograd, Paragraf Lex.

9. Mrvić Petrović, N., Koncepcija prekršaja u uporednom pravu, u: Bobar, K. (ur.), 2002, Zbornik - Prekršajna odgovornost, Beograd, Glosarijum.

10. Mrvić Petrović, N., Značaj naknadnog izvršenja poreske obaveze na kažnjavanje za poreske delikte, u: Kostić, J., Stevanović, A. (ur.), 2018, Finansijski kriminalitet, Beograd, Institut za uporedno pravo i Institut za kriminološka i sociološka istraživanja.

11. Podszun, R., Busch, C., Henning-Bodewig, F., Behördliche Durchsetzung des Verbraucherrechts? Darstellung und Systematisierung von Möglichkeiten und Defiziten der privaten Durchsetzung des Verbraucherschutzes sowie Einbeziehung der Kartellbehörden zu dessen Durchsetzung, Studie im Auftrag des Bundesministeriums für Wirtschaft und Energie, Februar 2018, (https://www.bmwi.de/Redaktion/DE/ Publikationen/Studien/behoerdliche-durchsetzung-des-verbraucherrechts.pdf? blob=publicationFile\&v=10, 20. 7. 2020). 


\section{PRAVNI IZVORI}

1. Directive 2011/83/EU of the European Parliament and the Council of 25 October 2011 on consumer rights, amending Council Directive 93/13/EEC and Directive 1999/44/EC of the European Parliament and the Council and repealing Council Directive 85/577/EEC and Directive 97/7/EC of the European Parliament and of the Council Text with EEA relevance, OJ L 304, 22. 11. 2011, pp. 64-88 (konsolidovana verzija od 1. 6. 2018. sa izmenama zbog usvajanja Direktive EU 2015/302 od 25. 12. 2015. - OJ L 326, p. 1). Konsolidovani tekst Direktive dostupan na: http://data.europa.eu/eli/dir/2011/83/2018-07-01 (25. 8. 2020).

2. Report from the Commission to the European Parliament and the Council on the application of Directive 2011/83/EU of the European Parliament and of the Council of 25 October 2011 on consumer rights, amending Council Directive 93/13/EEC and Directive 1999/44/EC of the European Parliament and of the Council and repealing Council Directive 85/577/EEC and Directive 97/7/EC of the European Parliament and of the Council COM/2017/0259 final, Document 52017DC0259, (https://eur-lex.europa.eu/ legal-content/EN/TXT/?uri=COM\%3A2017\%3A259\%3AFIN, 25. 8. 2020).

3. Zakon o inspekcijskom nadzoru, Sl. glasnik RS, br. 36/15, 44/18 - dr. zakon, 95/18.

4. Zakon o prekršajima, Sl. glasnik RS, br. 65/13, 13/16, 98/16 - odluka US, 91/19 - dr. zakon.

5. Zakon o varstvu potrošnikov (ZVPot), Uradni list RS, br. 98/04 sa kasnijim izmenama, poslednjim u br. 31/18 od 4. 5. 2018. Prečišćeni tekst dostupan na: http://www. pisrs.si/Pis.web/pregledPredpisa?id=ZAKO513, 10. 7. 2020.

6. Zakon o varstvu potrošnikov pred nepoštenimi poslovni praksi, Uradni list RS, br. 53/07.

7. Zakon o zaštiti potrošača, Sl. glasnik $R S$, br. 62/14, 6/16 - dr. zakon, 44/18 - dr. zakon. 


\title{
MISDEMEANOR LAW PROTECTION OF CONSUMERS
}

\author{
Nataša Mrvić Petrović \\ Slađana Jovanović
}

SUMMARY

The subject of this paper is misdemeanor law protection of consumers in Serbia, viewed in the context of positive, segmented (and therefore criticized) legal protection of consumers. Misdemeanor law protection (along with administrative law protection, to which attention has also been paid) is a subsidiary mechanism of legal protection, not so well connected with the primary one - private law protection. Based on the analysis of legal solutions (primarily related to misdemeanor law, but also administrative law protection of consumers) and examples of good practice in comparative legislation, and the recently published research, the shortcomings of the existing protection mechanism were pointed out, and suggestions for legislative improvements de lege ferenda were given, as well as to improve existing practices. The authors point out that the protection of consumer rights, interests and health should be linked to the issue of human rights, which implies the establishment of an efficient system of administrative and misdemeanor law protection, as well as organizational harmonization of private and public consumer protection mechanisms.

Key words: consumer rights, inspectional supervision, misdemeanor law protection, Consumer Protection Act. 